\section{Estudo \\ cobebate}

em Testão

Plamejamento

\title{
PAGAMENTO POR SERVIÇOS AMBIENTAIS: UMA ANÁLISE PARA O JARDIM BOTÂNICO BENJAMIM MARANHÃO, JOÁO PESSOA (PB)
}

\author{
Josimar Vieira dos Reis ${ }^{1}$, Jadson Freire da Silva ${ }^{2}$, Antônio Hélton Vasconcelos dos Santos ${ }^{3}$, \\ Elisabeth Regina Alves Cavalcanti Silva ${ }^{4}$
}

\begin{abstract}
Resumo: Este artigo versa sobre a análise da à Lei no 10.165/2013 que é a legislação estadual para o Pagamento por Serviços Ambientais (PSA) do Estado da Paraíba, demonstrando as possibilidades de um subprograma de PSA para o Jardim Botânico Benjamim Maranhão, na Cidade de João Pessoa - PB. Mostrando o potencial do PSA que estáo em execução no Brasil, como também programas que já tiveram seus términos. Por meio de pesquisa bibliográfica e documental sobre os serviços ambientais; economia ecológica/ambiental, e PSA. O mecanismo de comando e controle como o PSA, pode ser promissor para o Jardim Botânico Benjamin Maranhão e consequentemente a conservação da fauna e flora da Mata do Buraquinho, um importante ecossistema urbano que faz parte da Mata Atlântica. Por fim, ressalto que o PSA como uma contrapartida financeira para o protetor em troca da conservaçáo da natureza, pode trazer benefícios socioeconômicos, resgatar a dignidade social e trazer valores e saberes da natureza, muitas vezes esquecidos pelo homem, quando este enxerga os ecossistemas meramente como forma de capital e não de proteção ou conservação para a sua subsistência.
\end{abstract}

Palavras-chave: Biodiversidade. Legislação. Mata atlântica.

Abstract: This article deals with the analysis of Law No. 10,165 / 2013 and the state legislation for the Payment for Environmental Services (PSA) of the State of Paraíba, demonstrating the possibilities of a PSA subprogram for the Benjamim Maranhão Botanical Garden in the City of João Pessoa - PB. Showing the potential of the PSA that are running in Brazil, as well as programs that have already had their terms. Through bibliographic and documentary research on environmental services; ecological / environmental economy, and PES. The control and control mechanism like the PSA can be promising for the Benjamin Maranhão Botanical Garden and consequently the conservation of the fauna and flora of the Buraquinho Forest, an important urban ecosystem that is part of the Atlantic Forest. Finally, I emphasize that the PSA as a financial counterpart to the protector in exchange for the conservation of nature, can bring socio-economic benefits, rescue social dignity and bring values and knowledge of nature, often forgotten by man, when he sees the ecosystems merely as a form of capital and not of protection or conservation for their subsistence.

Keywords: Biodiversity. Legislation. Atlantic forest.

1 Doutorando em Desenvolvimento Urbano na Universidade Federal de Pernambuco - UFPE.

2 Doutorando em Desenvolvimento e Meio Ambiente na Universidade Federal de Pernambuco - UFPE.

3 Mestrando em Desenvolvimento e Meio Ambiente na Universidade Federal de Pernambuco - UFPE.

4 Professora de Engenharia Ambiental do Instituto Federal do Maranhão - IFMA. 


\section{INTRODUÇÁO}

Discutir sobre o Pagamento por Serviços Ambientais (PSA) resulta no conhecimento de alguns elementos relevantes que definem legalmente o meio ambiente, sendo categorizada nos seguintes aspectos: meio ambiente natural, meio ambiente artificial, meio ambiente cultural e meio ambiente do trabalho. Esta categorização possibilita a percepção que o meio ambiente não se restringe apenas ao que percebemos como natureza. Portanto, as decisōes para uma gestão ambiental coerente devem ser tomadas levando em consideração características físicas, biológicas e químicas do território, como também as transformaçōes antrópicas que inevitavelmente modificam o meio. Neste sentido, para um mecanismo de PSA existir não é obrigatório que o ambiente esteja em um estado de degradação; o mesmo pode ser conservado ou preservado.

$\mathrm{Na}$ verdade, os meios para se ter um PSA dependem muito das características de uso, uma vez que um mecanismo de PSA bem definido juridicamente e economicamente pode ser um importante aliado na conservaçáo ambiental. A literatura especializada define PSA como "uma transação voluntária onde um serviço ambiental bem definido está sendo comprado por um comprador, desde que o provedor assegure sua provisão." (WUNDER, 2005). Segundo Tacconi (2012) o Pagamento por Serviços Ambientais (PSA) é um esquema de um sistema transparente para a provisão adicional de serviços ambientais por meio de pagamentos condicionados a provedores voluntários.

O PSA vem demonstrando ser um mecanismo de comando e controle eficiente, visto que já existem no Brasil programas de sucesso, como o projeto "produtores de água e floresta" - bacia do guandu/RJ; Projeto Conservador de Águas - Extrema/MG; Oásis Apucarana/ Apucarana / PR entre outros. As iniciativas de programas PSA, no Brasil concentram-se, em sua maioria, nas regióes Sul e Sudeste. Sendo assim, ainda existem desafios e limitaçóes a serem superados, a fim de que esses programas ampliem seu alcance para outras regiōes.

Um dos maiores entraves para o PSA é a legislaçâo, que a nível nacional ainda tramita na Câmara Federal, sendo motivo de vários debates, uma vez que a bancada ruralista enxerga com maus olhos as políticas de PSA, alegando que trará retrocesso ao agronegócio. Porém, em alguns Estados brasileiros o PSA transforma paisagens e efetiva o homem do campo na sua terra, induzindo a conservação ambiental e o convívio pacifico do homem com a natureza. Sendo a legislação ambiental brasileira considerada uma das melhores do mundo, devido às diversas formas de contemplar as formas de uso e preservaçâo do meio ambiento, o PSA vem atuando nas formas de complemento para a lei, assegurando de forma consubstanciada em uma contrapartida financeira a conservaçáo do ambiente em parceria com os ambientalistas (conservadores da natureza), visto que nem sempre a abrangência da lei ambiental é suficiente para proteger o meio ambiente.

A histórica colonizaçáo brasileira, que atingiu diretamente o bioma Mata Atlântica e os atuais desmatamentos causados pelo homem observados nos rincóes do país, principalmente na região da Amazônia, fazem aumentar gradativamente as zonas urbanas e de agronegócio no território nacional. Consequentemente, nota-se as reduções das áreas conservadas e preservadas, isolando-as em muitos casos a grandes perímetros urbanos, como é o caso do jardim botânico Benjamin Maranhão, na Cidade de João Pessoa - PB, que é considerada o maior remanescente de Mata Atlântica em área urbana do Brasil. 
A proximidade de ambientes naturais com os centros urbanos, o forte desenvolvimento deste somados com a falta ou o inadequado zoneamento e fiscalização por meio dos órgãos competentes, podem causar intensos danos ao bioma de interesse, necessitando assim, de mecanismos que contribuam na conscientização e conservaçáo. Embasando-se na Lei ${ }^{\circ}$ 10.165/2013 que se refere a legislação estadual para o Pagamento por Serviços Ambientais (PSA) do Estado da Paraíba, este artigo tem como objetivo analisar o potencial para uma possível aplicação de um mecanismo PSA no Jardim Botânico Benjamin Maranhão e sua região de entorno, denominada mata do Buraquinho.

\section{REFERENCIAL TEÓRICO}

\subsection{Serviços ambientais e seu contexto geral}

O ser humano integra um sistema que engloba complexas, dinâmicas e contínuas interaçóes entre seres vivos e não vivos em seus ambientes físicos e biológicos, denominado ecossistema. Ecossistemas são observados como sistemas adaptativos, nos quais "propriedades sistêmicas macroscópicas como estrutura, relação produtividade-diversidade e padrōes de fluxos de nutrientes emergem de interaçóes entre os componentes, em um fluxo de retroalimentação, numa combinação de efeitos pelo equilíbrio dinâmico evolutivo" (ANDRADE; ROMEIRO, 2009, p. 3).

A Convenção sobre Diversidade Biológica (CDB) em seu Artigo $2^{\circ}$ define ecossistema como um "complexo dinâmico de comunidades vegetais, animais e de microrganismos e o seu meio inorgânico que interagem como uma unidade funcional" (BRASIL, 2000a). Nesses ecossistemas ocorrem diversas interaçóes biológicas (meio biótico mais meio abiótico), resultando em importantes processos naturais que garantem a sobrevivência das espécies e têm a capacidade de prover serviços que satisfaçam direta e indiretamente as necessidades do homem, apresentando-se como serviços ambientais. Os serviços ecossistêmicos ou ambientais são definidos como todos os benefícios gerados gratuitamente pelos ecossistemas, referindo-se tanto a bens quanto a serviços propriamente ditos (MEDEIROS et al, 2011).

Há autores, como Guedes e Seehusen (2011), que entendem serviços ambientais e ecossistêmicos como sinônimos. Já Tôsto et al. (2012) diferenciam estes dois tipos de serviços; para estes autores, serviços ecossistêmicos são os benefícios diretos e indiretos providos pelo funcionamento dos ecossistemas, sem a interferência humana; já os serviços ambientais são os benefícios gerados por açôes de manejo do homem nos sistemas naturais ou agroecossistemas, o que serviria para manter a oferta de serviços ecossistêmicos pela natureza.

O conceito de serviço ambiental ou ecossistêmico mais aceito pelos pesquisadores no âmbito acadêmico e literário é o desenvolvido pelas Organizaçóes das Naçóes Unidas (ONU) muito bem resumido no relatório da Avaliação Ecossistêmica do Milênio (EAM, 2005), que classifica os serviços prestados pela Natureza em Serviços de Suporte, Aprovisionamento, de Regulação e Culturais, conforme Quadro 01. 
Quadro 01 - Classificação e Definição dos Serviços Ambientais segundo a ONU

\begin{tabular}{|c|c|}
\hline SERVIÇOS & CONCEITOS \\
\hline Serviços de Provisão ou Abastecimento & $\begin{array}{c}\text { Sáo os produtos obtidos diretamente dos } \\
\text { ecossistemas (alimento, água, fibras, } \\
\text { matéria-prima, plantas medicinais etc.). }\end{array}$ \\
\hline Serviços de Regulação & $\begin{array}{c}\text { São os benefícios obtidos da regulação dos } \\
\text { ecossistemas (regulaçáo climática, } \\
\text { manutenção e purificação da qualidade do ar } \\
\text { e da água etc.). }\end{array}$ \\
\hline Serviços Culturais & $\begin{array}{c}\text { São os benefícios não-materiais obtidos } \\
\text { através dos ecossistemas (lazer, beleza } \\
\text { cênica, ecoturismo, geração de } \\
\text { conhecimentos, valores espirituais etc.). }\end{array}$ \\
\hline Serviços de Suporte ou Apoio & $\begin{array}{c}\text { São os serviços necessários para a produção } \\
\text { de todos os outros serviços (reciclagem dos } \\
\text { nutrientes, produçáo primária, formaçáo e } \\
\text { retençấo do solo, provisão de hábitat, } \\
\text { gerenciamento do lixo etc.). }\end{array}$ \\
\hline
\end{tabular}

Fonte: EAM, (2005).

Dificilmente é observado um serviço ambiental sendo prestado isoladamente, isto quer dizer que podem ser fornecidos inúmeros serviços em uma unidade de conservação interligados entre si, como por exemplo: conservação da biodiversidade, contribuição para a melhoria do corpo hídrico, manutenção da ciclagem de nutrientes, regulaçáo do microclima, dentre outros. Entretanto, nem sempre é possível haver clara delimitação do serviço, e é por meio das funçóes ecossistêmicas que se dá a geração das delimitaçóes dos serviços ambientais.

Andrade e Romeiro (2009) defendem que uma função ecossistêmica gera um determinado serviço ecossistêmico direta ou indiretamente apropriáveis pelo ser humano, incorporando a noção de utilidade antropocêntrica. Desta forma, uma função passa a ser considerada um serviço ecossistêmico ou ambiental quando ela apresenta possibilidade e potencial de ser utilizado para fins humanos.

Os serviços ecossistêmicos foram definidos por Daily (1997) como os serviços prestados pelos ecossistemas naturais e suas espécies para a manutenção e permanência do homem no planeta. Os serviços ambientais estão mais relacionados com os resultados desses processos, ou seja, estão mais focados nas atividades e benefícios percebidos pelo homem (VEIGA NETO; MAY, 2010; WHATELY; HERCOWITZ, 2008).

Embora existam sutis diferenças conceituais, os dois termos acima citados são intercambiáveis e utilizados para indicar os mesmos processos. Considera-se neste trabalho o termo como serviços ambientais e não somente ecossistêmicos, uma vez que os serviços ambientais são serviços oferecidos pelos ecossistemas, mas que são percebidos diretamente pelas pessoas, tendo dessa forma, uma relação direta homem/natureza.

Essas relações homem/natureza observadas nos serviços ambientais acontecem de muitas formas e intensidades (Figura 01). A Millenium Ecosystem Assessment propóe 
interconexóes entre as várias categorias dos serviços ambientais e o bem-estar humano; os serviços de provisão, por exemplo, são indispensáveis para a saúde e para uma boa qualidade de vida.

Figura 01 - Relaçóes dos serviços ambientais e os constituintes do bem-estar humano

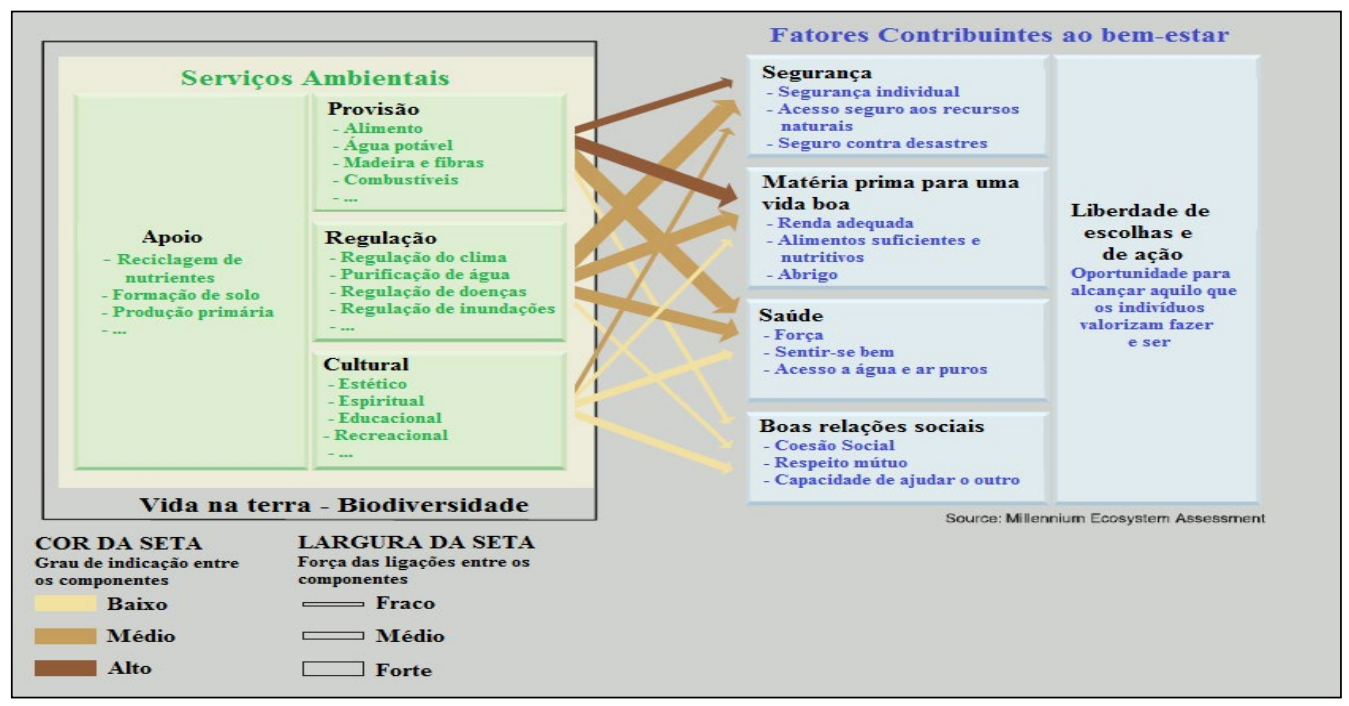

Fonte: MEA, (2005).

Observando as ligaçóes entre os serviços e o bem-estar humano, fica explícita a importância desses serviços para as condiçóes de vida na terra e para a busca de uma sustentabilidade. Portanto, qualquer ação que vise incrementar a qualidade de vida das populaçóes e acelerar o processo de desenvolvimento deve reconhecer sua relevância, como cita Andrade (2010). Segundo a Millennium Assessment (2005), a população do planeta é totalmente dependente dos seus ecossistemas e dos serviços que eles oferecem, incluindo alimentos, água, gestão de doenças, regulação climática, satisfação espiritual e apreciação estética; e neste contexto, é essencial observar as características dos ecossistemas para produção de serviços ambientais a fim de realizar a melhor gestão dos recursos.

\subsection{A questáo ecológica no pensamento econômico}

A partir dos anos 1970 que se passou a reconhecer a existência de uma crise ambiental, cujos sintomas tinham sua origem numa concepçáo da economia, que encarava a natureza como fonte inexaurível de recursos e matéria-prima para sustentar as atividades humanas (CAVALCANTI, 2004). A constatação da necessidade de mudança deste paradigma foi sendo historicamente construída, tendo o relatório Limitsof Growth (Limites do Crescimento), publicado pelo Clube de Roma em 1972, constatando que os ritmos do crescimento econômico estavam colocando em crise a sobrevivência do ser humano.

A divulgaçâo do relatório do Clube de Roma em 1972, intitulado "Limites do Crescimento", popularizou a tese de que o aumento populacional seria incompatível com 
o estoque de recursos naturais, evidenciando dificuldades para a produção de alimentos e gerando danos ambientais (MOTA, 2001). Considerada como um marco do ambientalismo global, segundo Mota (2001), a Conferência de Estocolmo, realizada em junho de 1972, concedeu legitimidade às preocupaçóes ambientais. Ela também ajudou a fortalecer os grupos ambientalistas na promoção de desenvolvimento de políticas correlacionadas ao uso do meio ambiente.

Quinze anos depois de Estocolmo, em 1987, a Organização das Naçóes Unidas ONU publicou o relatório da Comissão Mundial sobre o Meio Ambiente e Desenvolvimento - CMMAD, titulado "Nosso Futuro Comum". Esse trabalho seguiu uma perspectiva diferente em comparação ao relatório do Clube de Roma. Enquanto este defendia a paralisação do crescimento econômico e demográfico, o relatório Nosso Futuro Comum (ou Relatório Brundtland) tinha a intenção de disseminar a ideia de que não havia oposição entre desenvolvimento e meio ambiente, mas relação positiva. Da necessidade de conciliar crescimento econômico com degradação ambiental, surge o conceito de desenvolvimento sustentável. Atividade econômica, o meio ambiente e o bem-estar social são o tripé desse novo conceito.

Mesmo diante das atuaçóes e relatórios ambientais promovidos pelos grandes encontros de cientistas, nos dias atuais a problemática ambiental vivida reflete a contínua intervenção que o homem promove na natureza, causando desequilíbrios ecossistêmicos, comprometendo a vida dos seres vivos e colocando em perigo a sustentabilidade da terra. Segundo Barreto (2009) a possibilidade de esgotamento dos recursos naturais e a destruição cada vez mais crescente de diversos ecossistemas é uma realidade atual resultante da interação homem-natureza, em decorrência do avanço do desenvolvimento econômico e sua produção destrutiva.

Concomitando com as ideias promovidas no Clube de Roma surge o termo ecodesenvolvimento, proposto por Ignacy Sachs, na década de 1970, como uma expressão de crítica ao sistema econômico. $\mathrm{O}$ conceito propóe equilibrar a necessidade do desenvolvimento com a racionalidade no uso dos recursos ambientais, caracterizandose por ser um desenvolvimento socialmente desejável, ecologicamente sustentável e economicamente viável (ROCHA, 2004; SACHS, 1986). A partir de então, ao mesmo tempo em que a economia convencional se atentava em agregar aspectos da sustentabilidade em seus pressupostos, foram surgindo outras correntes de pensamento que se formaram a partir do reconhecimento de que a economia convencional possuía argumentos insuficientes e inadequados para lidar com a problemática ambiental e nesse contexto emergem novas correntes de pensamento que buscam aproximar as discussóes no âmbito da economia e o ambiente, dentre elas cita-se a Economia Ambiental, de base neoclássica, e a Economia Ecológica que se diferencia por compreender a economia como subsistema da natureza (ANDRADE, 2010).

A primeira, de origem neoclássica, chamada de economia ambiental, reconhece a importância dos recursos naturais, embora não os veja, no longo prazo, como um limite absoluto à expansão da economia. Nesta concepção, a suposição é a de que os limites impostos pela disponibilidade de recursos naturais podem ser indefinidamente superados pelo progresso técnico e científico (MARTINS, 2007). 
Outra característica da economia ambiental é a tentativa de traduzir as externalidades negativas (impactos ambientais, recursos exauridos etc.) em valores financeiros a serem levados em consideraçáo ou internalizados pelos processos produtivos como forma de buscar o desenvolvimento sustentável (CAVALCANTI, 2004).

A segunda linha de pensamento é a Economia Ecológica que nota o sistema econômico como uma subparte de algo maior que o domina, no caso a natureza, e a está impóem uma restriçấo absoluta à sua expansão. $\mathrm{O}$ progresso científico e tecnológico, nesse caso, também é importante para aumentar a eficiência no uso dos recursos naturais, porém este não possibilita a substituição ilimitada destes mesmos recursos. Logo, permanece a discordância de que o sistema econômico possa expandir sem levar em consideraçấo a capacidade de suporte do planeta (CAVALCANTI, 2010; CECHIN; VEIGA, 2010).

Nos dias atuais um dos maiores desafios que a humanidade enfrenta é a questáo da compatibilidade entre a conservaçáo ambiental e o crescimento econômico, onde vem se observando discussóes desse tema a alguns anos. Entretanto, devido ao avanço desenfreado da degradaçáo do ambiente e os efeitos irreversíveis que ele pode acarretar, o problema tem se tornado cada vez mais relevante. Sendo assim, identificar os bens e serviços de uma área protegida e mensurar seus valores tal como a valoraçáo ambiental promove, embora seja importante para a economia e meio ambiente, não é um processo simples. A mensuração de valores abarca produtos sensíveis como a recreação e turismo, fauna e flora, recursos genéticos, abastecimento de água, pesquisa e educação, entre outros; considera-se através de metodologias qual o valor que a sociedade atribui aos bens e serviços de uma área protegida, objetivando o bem-estar das pessoas (PUGAS, 2006).

Figueroa (2005) nota a importância da valoração dos recursos naturais ou de benefícios trazidos pela natureza, mas sem perder de vista as limitaçôes insuperáveis desta tentativa de traduzir, em termos monetários, valores tais como os de existência (valores culturais e éticos, por exemplo) que podem variar no tempo e no espaço. Por esse motivo e complexidade, Cunha (2014) enfatiza que a valoração, embora seja feita por meio de métodos que busquem dar conta da complexidade inerente aos ecossistemas, ainda mantém pequenas discrepâncias nos resultados finais devido a sua subjetividade.

Santana (2002) complementa comentando que a valoração para benefício ambiental que vise a melhorar a qualidade ambiental é uma tarefa extremamente árdua, principalmente quando se considera a inexistência de um mercado para esses bens. Uma forma de valorar economicamente um recurso natural seria determinar o quanto melhor ou pior estará o bem-estar das pessoas devido a mudanças na quantidade de bens e serviços ambientais, seja na apropriação por uso ou não (MOTTA, 2006).

Neste sentido, Pearce (2001) argumenta que expressar o valor econômico da biodiversidade torna-se um passo fundamental na conservação. As pressôes para reduzir a biodiversidade sáo táo grandes que as chances de se introduzir algum incentivo para a sua proteção, por mais limitado que seja, incrementam as chances de consumação do que se não existisse valor algum. É preocupação não recente das economias ambiental e ecológica, internalizar os impactos antrópicos sobre o meio ambiente provocado pelo avanço depredativo nos ecossistemas em busca de soluçóes para o abastecimento das necessidades 
humanas de consumo. A valoração ambiental vem ao encontro dos anseios de conservação e exploração sustentáveis.

Na visão de Sukhdev (2010), quantificar e avaliar serviços dos ecossistemas não é diferente de quantificar e valorar bens e serviços produzidos pelos seres humanos; em ambos os casos existem a necessidade de se garantir qualidade, reduzir pobreza e se pensar no bemestar dos indivíduos. Para Turner et al. (2003) o uso monetário como critério de mensuração dos benefícios ofertados pela natureza é capaz de estabelecer uma relação transparente com os outros usos de seus ativos e atributos, já que o mercado e a economia são amplamente difundidos em bases monetárias. Groot (1992) apud Tafuri (2008) sinalizou alguns motivos para valoração, destacando entre eles os pontos: valor da conservação, valor do uso da terra, valor da função ambiental, estudo de risco ambiental e estudo de impacto ambiental. A valoração da conservaçáo procura garantir que o uso do ecossistema seja sustentável; o seu objetivo é o de determinar o valor da proteçáo de certas espécies para determinar prioridade de proteção baseados em critérios como diversidade biológica, riqueza e raridade das espécies.

Segundo Sinisgalli (2005), a valoraçáo econômica ambiental procura definir o valor do recurso e serviço ambiental natural, com base na equivalência entre a disposição de abrir mão deste recurso, em termos de ganho econômico ou no quanto as pessoas estáo dispostas a investir na sua manutenção. Em outras palavras, a valoração ambiental procura refletir o quanto as pessoas estáo dispostas a pagar para manter o seu bem-estar ou receber para abrir máo dele. E assim, a partir do ano de 1990, veio a surgir diversos trabalhos acadêmicos voltados a atribuir valores aos serviços proporcionados pela natureza, provendo desta forma, refinamentos e novas metodologias para valorar (ou mensurar) ambientes naturais diversos.

\subsection{Pagamento por serviços ambientais conceito e fundamentaçáo}

Durante muito tempo a economia de mercado não considerava os impactos de suas atividades sobre o meio ambiente, ou seja, a economia excluía qualquer conexáo entre sistemas ecológicos e as atividades de consumo e produção dos sistemas econômicos (CONSTANZA et al., 2012). Dentro do esquema de fluxo monetário, o capital natural não era considerado, sendo a natureza relegada à mera "externalidade" (CAVALCANTI, 2010). Em termos econômicos, os serviços ambientais ou ecossistêmicos têm características de bens públicos e são tipicamente definidos e tratados como externalidades, entendida como os efeitos ocasionados por um agente econômico sobre outros agentes, sem a devida compensação. Para Coase (1960) a solução dos problemas ocasionados pelas externalidades compete a uma negociação privada até que as partes afetadas alcancem uma solução eficiente.

A base teórica de esquemas de pagamentos por serviços ambientais (PSA) não é recente, sendo que os conceitos chaves de externalidades e bens públicos datam pelo menos do início do século XX. No entanto, somente nas últimas décadas o PSA vem ganhando espaço em publicaçóes em todo mundo, assim como têm servido de base para diversas experiências práticas de políticas públicas.

Observam-se os primeiros esquemas de PSA na década de 1960, sendo derivados do Teorema de Coase, o qual afirma que através de negociaçóes os agentes internalizam as 
externalidades e atingem eficiência, independentemente da dotação inicial dos direitos de propriedade e na ausência de custos de transação (KOSOY et al, 2007).

O Teorema de Coase foi formulado por Ronald Coase (economista norte-americano) e refere que as externalidades ou ineficiências econômicas podem ser, em determinadas circunstâncias, corrigidas e internalizadas pela negociação entre as partes afetadas, sem necessidade de intervenção de uma entidade reguladora. As referidas circunstâncias necessárias para que tal seja possível são segundo Coase (1960): a possibilidade de negociação sem custos de transação e a existência de direitos de propriedade garantidos e bem definidos.

Uma possível solução para as externalidades ambientais seria a compensação aos proprietários pelos serviços ecossistêmicos ou ambientais por eles fornecidos, esse é o princípio dos mecanismos de Pagamento por Serviços Ambientais (PSA). Para Engel, Pagiola e Wunder (2008), o PSA pode ser considerado como uma tentativa de aplicação pratica do Teorema de Coase, uma vez que os problemas das externalidades negativas podem ser superados através de negociação particular entre as partes envolvidas, gerando assim incentivos financeiros para os agentes fornecerem serviços ambientais. Segundo Milaré (2013) o termo externalidades é empregado para explicar os efeitos negativos ao meio ambiente, decorrentes de determinadas atividades econômicas, que são percebidos pela coletividade, ao contrário do lucro, que é percebido pelo produtor privado.

Deste modo, surgiram concomitantemente diversas definições e questionamentos quanto ao PSA que reforçam a necessidade do mesmo (Wunder; Kanounnikoff, 2009). A despeito das inúmeras definiçóes para o PSA, uma delas é amplamente usada e o define como "uma transação voluntária, na qual um serviço ambiental bem definido, ou um uso da terra que possa assegurar este serviço, é adquirido por, pelo menos, um comprador de no mínimo, um provedor, sob a condição de que ele garanta a provisão do serviço (condicionalidade)".

Um importante instrumento jurídico que reforça as ações de Pagamento por Serviços Ambientais é o princípio protetor-recebedor, à medida que estimula a participação do cidadão na proteção do ambiente, fazendo com que continue prestando serviços indispensáveis à preservação da biodiversidade e da própria dignidade humana. Assim, aqueles que praticam ação favorável, isto é, que auxiliem na conservação do ambiente, permitindo que a natureza preste serviços ambientais à sociedade, devem receber alguma espécie de compensação, sendo a pecuniária a mais comum. O princípio do protetor-recebedor, que começa a ser debatido sobre pagamento por serviços ambiental, propóe o pagamento aqueles agentes cuja ação promove o incremento dos serviços ambientais prestados pela natureza (NUSDEO, 2012).

Para Nusdeo (2012) as práticas humanas podem degradar ou destruir as condiçóes de prestação do serviço ou podem, ao contrário, reforçá-las e protegê-las, merecendo então uma compensação. As políticas públicas, por sua vez, devem prestigiar o princípio protetor-recebedor, de modo a estimular a conduta do cidadão mediante contrapartida, para a concretização de açóes efetivas em prol do meio ambiente. Com assento na legislação de regência, o protetor-recebedor, voluntário, promove a salvaguarda dos recursos naturais e, consequentemente, a conservação do meio ambiente. Os sistemas de Pagamentos por Serviços Ambientais (PSA) têm princípio básico no reconhecimento de que o meio ambiente 
fornece gratuitamente uma gama de bens e serviços que são de interesse direto ou indireto do ser humano, permitindo sua sobrevivência e seu bem-estar (GELUDA; YOUNG, 2005).

Segundo a Foodand Agriculture Organization - FAO (2004) esquemas de Pagamentos por Serviços Ambientais são mecanismos de compensação flexíveis pelos quais os provedores de serviços ambientais são pagos pelos usuários destes serviços. Os PSAs são considerados mecanismos promissores para o financiamento da proteção e restauraçáo ambiental, assim como forma de complementar e reforçar as regulaçōes existentes. Por sua vez, Altmann (2011) afirma que o PSA deve ser visto como complemento dos atuais instrumentos de "comando e controle", tornando efetiva a tarefa de proteção ambiental. Assim, as políticas ambientais e econômicas devem andar juntas para garantir o uso sustentável dos recursos naturais (BECKER, 2005).

A maior parte dos esquemas de PSA existentes trabalha com quatro grandes grupos de serviços ambientais: beleza cênica, sequestro de carbono, conservação da biodiversidade e proteção de bacias hidrográficas (LANDELL-MILLS; PORRAS, 2002). Segundo Wunder (2009) os principais serviços ambientais comercializados são: água, biodiversidade, captura de carbono, qualidade dos solos e beleza cênica. Trata-se assim, de um instrumento econômico normativo destinado a dirigir e estimular comportamentos para a consecuçáo do objetivo (jurídico, político e econômico) pré-estabelecido de garantir a preservação dos processos ecológicos essenciais por meio da remuneração do conservador, provedor e/ou viabilizador. (MILARÉ, 2013, pag. 128)

De maneira geral, o Pagamento por Serviços Ambientais (PSA) é um instrumento de mercado para financiamento da conservação que oferece remuneração e recompensa àqueles que protegem e promovem os serviços ambientais ao mesmo tempo em que estimula os beneficiários destes serviços a pagar por sua manutenção (ENGEL, PAGIOLA e WUNDER, 2008; WUNDER, 2009). De acordo com Wunder (2009) para que haja um esquema de PSA são necessários cinco elementos: transação voluntária; Serviço ambiental bem definido; que seja comprado; tenha um provedor; sob a condição de que o provedor garanta a provisão deste serviço. Fundamentado por esses cinco elementos o PSA poderá ser aplicado com a devida satisfatoriedade e notoriedade, atuando diretamente no bem-estar social, desenvolvimento econômico local e conservação ambiental.

\subsection{Legislaçáo de pagamento por serviços ambientais no Brasil}

O Brasil carece de uma legislação específica sobre PSA a nível nacional, porém algumas das Leis existentes abordam o tema ou podem ser interpretadas como uma forma de PSA. A primeira lei a ser levantada é a Lei Florestal (Lei 12.651/2012), que substituiu o Código Florestal de 1965 e provocou diversas mudanças no modo de ocupação do território nacional, trazendo implicaçôes ao meio ambiente, através do avanço da fronteira agrícola e da anistia de recomposiçâo de áreas desmatadas ilegalmente (PACKER, 2015). No entanto, a Lei Florestal também trouxe novas ferramentas de incentivo à conservação do meio ambiente, tal como o Artigo 41, que prevê o Pagamento por Serviços Ambientais descrevendo este como uma remuneração monetária ou não, às atividades de conservação e manutenção dos ecossistemas. 
A Política Nacional de Recursos Hídricos - PNRH (Lei no 9.433/1997) também mantém traços com o PSA no que tange a água. A PNRH demonstra a preocupação com a conservação de áreas para qualidade de água, tendo como instrumento a cobrança pelo uso de recursos hídricos a fim de obter recursos financeiros para o financiamento dos programas e intervençóes contemplados nos planos de recursos hídricos. Os planos possuem metas de racionalização de uso, aumento da quantidade e melhoria da qualidade dos recursos hídricos disponíveis (BRASIL, 1997). Mesmo sem mencionar o PSA, pode-se interpretar que a Política Nacional de Recursos Hídricos é um instrumento legal que colocou um início à ideia acerca do tema, dando um valor à quantidade e qualidade da água.

Os artigos 47 e 48 da Lei 9.985/2000 que institui o Sistema Nacional de Unidades de Conservação (SNUC) também não mencionam PSA de forma explícita, porém podese interpretar que se trata de uma abordagem similar do tema, apesar de imposta, quando menciona o pagamento para proteção de áreas a fim de se obter qualidade de recursos hídricos.

Todavia, alguns estados e municípios brasileiros já criaram leis específicas de PSA, como observado na Tabela 1, onde está descrita as leis e suas especificidades.

Tabela 1: Relaçáo de Leis Estaduais relacionadas ao Pagamento por Serviços Ambientais em alguns dos Estados Brasileiros

\begin{tabular}{l|l|l}
\hline \multicolumn{1}{c|}{ ESTADO } & \multicolumn{1}{|c}{ LEI No } & \multicolumn{1}{c}{ ESPECIFICIDADE } \\
\hline Minas Gerais & Lei $17.727 / 08$ & $\begin{array}{l}\text { Política Estadual de Recursos Hídricos e Política Florestal e de } \\
\text { proteçáo à biodiversidade no Estado. }\end{array}$ \\
\hline Acre & Lei $2.308 / 10$ & $\begin{array}{l}\text { Sistema Estadual de Incentivos a Serviços Ambientais - SISA; } \\
\text { Programa de Incentivos por Serviços Ambientais - ISA; } \\
\text { Carbono e demais Programas de Serviços Ambientais e } \\
\text { Produtos Ecossistêmicos do Estado. }\end{array}$ \\
\hline Amazonas & Lei $3.135 / 07$ & Política Estadual de Mudanças Climáticas \\
\hline Bahia & Lei $13.233 / 15$ & $\begin{array}{l}\text { Política Estadual de Pagamento por Serviços } \\
\text { Ambientais; Programa Estadual de Pagamento por } \\
\text { Serviços Ambientais }\end{array}$ \\
\hline Santa Catarina & Lei $15.133 / 10$ & Política Estadual de Serviços Ambientais \\
\hline Espírito Santo & Lei $9.864 / 12$ & Programa de Pagamento por Serviços Ambientais - PSA \\
\hline Paraná & Lei 17.134/12 & Pagamento por Serviços Ambientais \\
\hline Rio de Janeiro & Lei $3.239 / 99$ & Política Estadual de Recursos Hídricos \\
\hline Tocantins & Lei $1.917 / 08$ & $\begin{array}{l}\text { Política Estadual sobre Mudanças Climáticas, Conservaçáo } \\
\text { Ambiental e Desenvolvimento Sustentável do Estado de } \\
\text { Tocantins }\end{array}$ \\
\hline São Paulo & Lei 13.798/09 & Política Estadual de Mudanças Climáticas \\
\hline Parába & Lei 10.165/13 & Política Estadual de Enfrentamento às Mudanças Climáticas \\
\hline
\end{tabular}




\begin{tabular}{l|l|l}
\hline \multicolumn{1}{c|}{ ESTADO } & \multicolumn{1}{|c|}{ LEI No } & \multicolumn{1}{c}{ ESPECIFICIDADE } \\
\hline Pernambuco & Lei 15.809/16 & $\begin{array}{l}\text { Política Estadual de Pagamento por Serviços Ambientais cria } \\
\text { o Programa Estadual de Pagamento por Serviços Ambientais } \\
\text { e o Fundo Estadual de Pagamento por Serviços Ambientais de } \\
\text { Pernambuco }\end{array}$ \\
\hline Mato Grosso & Lei $9.878 / 13$ & Lei de REDD+ \\
\hline Goiás & Lei n. $18.104 / 13$ & Lei Florestal \\
\hline
\end{tabular}

Fonte: Autores, (2017).

Segundo Brasil (2011) a existência de uma legislação específica é importante para se criar programas de PSA associados às políticas, garantindo o repasse de recursos e principalmente reconhecendo a importância dos serviços ecossistêmicos para a sociedade. De acordo com a International Union for Conservation of Nature - IUCN (2000), os aspectos sociais, ambientais e econômicos acerca de projetos de PSA já foram bastante considerados, entretanto a questão legislativa recebeu menos análises.

Observa-se um grande Projeto de Lei (PL) específico sobre Pagamentos por Serviços Ambientais PL - 792/2007 em tramitação na Câmara dos Deputados, onde, o PL e seus 10 apensos instituem a Política Nacional de Pagamentos por Serviços Ambientais (PACKER, 2015) (CFT, 2007). Por mais que alguns estados brasileiros estejam bem avançados com as legislaçóes próprias de PSA, a (PL) 792/2007 vem enfrentando muitos problemas no congresso, principalmente com a bancada ruralista que vê uma ameaça ao agronegócio o avanço da lei.

\section{METODOLOGIA}

Este artigo, face às concepçóes definidas na literatura sobre objetivos de uma pesquisa, pode ser categorizado como uma pesquisa exploratório-descritiva, tratando-se de um artigo que visa analisar e descrever sobre a legislação de PSA do Estado da Paraíba, fazendo apontamentos para a gestão do Jardim Botânico Benjamin Maranhão, localizado na cidade de João Pessoa-PB. Para isto, foi utilizada a pesquisa bibliográfica e documental acerca dos serviços ambientais, economia ambiental e ecológica e Pagamento por Serviços Ambientais (PSA).

A pesquisa bibliográfica e documental tem por finalidade conhecer as diferentes formas de contribuição científica que se realizaram sobre determinado assunto ou fenômeno. Baseado em material já publicado, constituído principalmente de artigos de periódicos científicos, documentos, livros, trabalhos de conclusão de curso, material disponibilizado na Internet (VASCONCELOS, 2005). A abordagem deste artigo é de uma pesquisa qualiquantitativa. Com base em dados primários e secundários (GIL, 2010).

A área de estudo corresponde ao Jardim Botânico Benjamim Maranhão. Possuindo aproximadamente 329,39 ha e inserido na Mata do Buraquinho (515 ha), o Jardim Botânico está localizado no centro urbano da capital paraibana e caracteriza-se como Floresta Estacional Semidecidual (IBGE, 1992), constituindo um dos principais remanescentes de Mata Atlântica do Estado (Figura2). 
Figura 02 - Mapa de Localização do Jardim Botânico Benjamin Maranhão/Mata do Buraquinho - Cidade de João Pessoa/PB

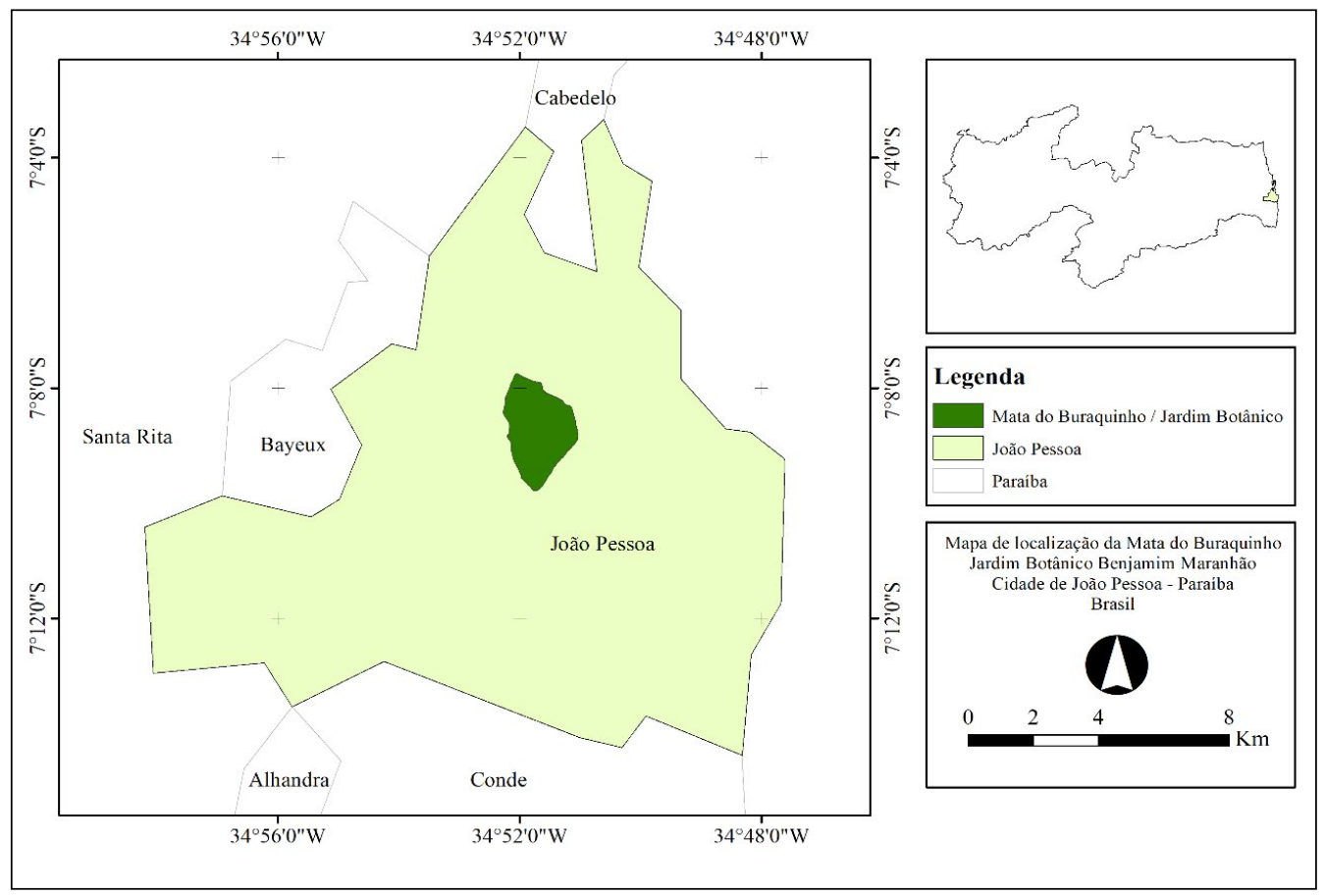

Fonte: Autores, (2018).

\section{DESCRIÇÃO E ANÁLISE DOS RESULTADOS}

\subsection{Um olhar sobre a legislação de Pagamento por Serviços Ambientais (PSA) do Estado da Paraíba}

O Brasil possui 78 iniciativas de PSA para o bioma Mata Atlântica, destas, nenhuma está localizada na Paraíba. No entanto, um grande passo foi dado com a promulgação da Lei no 10.165, de 25 de novembro de 2013, que dispóe sobre a Política Estadual de Pagamentos por Serviços Ambientais (PEPSA) e autoriza a instituição do Fundo Estadual de Pagamento por Serviços Ambientais.

A Lei no 10.165 , de 25 de novembro de 2013 de PSA na Paraíba, dispóe de 14 artigos que se dividem entre política estadual de pagamento por serviços ambientais, autoriza instituir o fundo estadual de pagamento por serviços ambientais. Trazendo a definição e entendimento sobre o disposto inicial sobre os serviços ambientais. Conforme o Quadro 2. 


\section{Quadro 2. Conceito sobre os serviços ambientais na legislação Paraibana}

Serviços ambientais ou ecossistêmicos: benefícios relevantes para a sociedade gerados pelos ecossistemas, em termos de manutenção, recuperação ou melhoramento das condiçóes ambientais, nas seguintes modalidades.

a) serviços de provisão: os que fornecem diretamente bens ou produtos ambientais utilizados pelo ser humano para consumo ou comercialização

b) serviços de suporte: os que promovem a ciclagem de nutrientes, a decomposição de resíduos, a produção, a manutenção ou a renovação da fertilidade do solo, a polinização, a dispersão de sementes, o controle de populaçóes de potenciais pragas e de vetores potenciais de doenças humanas, a proteção contra a radiação solar ultravioleta, a manutenção da biodiversidade e do patrimônio genético, entre outros que mantenham a perenidade da vida na terra.

c) serviços de regulação: os que promovem o sequestro de carbono, a purificaçáo do ar, a moderação de eventos climáticos extremos, a manutenção do equilíbrio do ciclo hidrológico, a minimização das enchentes e das secas, e o controle dos processos críticos de erosáo e de deslizamentos de encostas, entre outros que concorram para a manutenção da estabilidade dos processos ecossistêmicos.

Fonte: Autores, (2018).

Nota-se que no PSA Paraibano, os serviços ambientais culturais não estão enquadrados na legislação mesmo em alguns locais no Estado da Paraíba possuindo um bom potencial para estes serviços, uma vez que existem importantes cenários de beleza cênicas, propicia a diversas práticas do serviço ambiental cultural, tal como o ecoturismo; recreação; pesquisa cientifica; educação ambiental e práticas religiosas.

Nas diretrizes sobre da política paraibana de Pagamentos por Serviços Ambientais, se apresentam importantes elementos para a conservação do meio ambiente, tais como a priorização do pagamento pelos serviços ambientais prestados em ecossistemas sob maior risco socioambiental e a utilização do pagamento por serviços ambientais como instrumento de promoção do desenvolvimento social, econômico e cultural das populaçóes tradicionais, dos povos indígenas e dos agricultores familiares. Assim, fica criado o Programa Estadual de Pagamentos por Serviços Ambientais (PROPSA), com objetivo de efetivar a Política Estadual de Pagamentos por Serviços Ambientais (PEPSA) no âmbito estadual, em especial no que tange ao pagamento desses serviços pelo Estado (PARAÍBA, 2013). Segue estrutura do PROPSA do Estado da Paraíba, conforme Quadro 3.

\section{Quadro 3. Subprogramas de PSA do Estado da Paraíba}

I - Subprograma Água: destinado ao pagamento por ações e iniciativas que promovam a conservação e o melhoramento da quantidade e qualidade dos recursos hídricos, prioritariamente em bacias hidrográficas de baixa disponibilidade hídrica e com importância para o abastecimento humano e para a dessedentação de animais.

II - Subprograma Unidades de Conservação da Natureza, destinado ao pagamento por açóes e iniciativas que promovam a conservação, a recuperação ou a preservação do ambiente natural nas áreas de Unidades de Conservação e em respectivas zonas de amortecimento, bem assim aos instituidores de Reserva Particular do Patrimônio Natural - RPPN. 
III - Subprograma Reflorestamento e Recuperação de Áreas Degradadas: destinado ao pagamento por açóes e iniciativas de recuperação e conservação dos solos e recomposição da cobertura vegetal de áreas degradadas, por meio do plantio exclusivo de espécies nativas arbóreas ou arbustivas ou em sistema agroflorestal.

IV - Subprograma Remanescentes Vegetais em áreas Urbanas e Periurbanas: destinado ao pagamento por açóes e iniciativas de preservação de remanescentes vegetais de importância para a manutenção e o melhoramento da qualidade do ar, dos recursos hídricos e do bem-estar da população.

V - Subprograma Captura e Retenção de Carbono nos Solos: destinado ao pagamento por açôes e iniciativas de uso, manejo e conservaçáo dos solos que promovam a captura e o armazenamento de carbono.

Fonte: Autores, (2018).

Na última parte da legislação do PSA do estado da Paraíba é tratada a criação do fundo de PSA do Estado denominado Fundo Estadual de Pagamento por Serviços Ambientais FunPSA, de natureza contábil, com a finalidade de financiar as ações do Programa Federal de Pagamento por Serviços Ambientais (PROPSA), segundo os critérios estabelecidos nesta Lei e em seu regulamento, com as seguintes fontes de recursos: I - dotaçóes consignadas na Lei Orçamentária Anual e em seus créditos adicionais; I - dotaçóes consignadas na Lei Orçamentária Anual e em seus créditos adicionais; II - recursos decorrentes de acordos, ajustes, contratos e convênios celebrados com órgáos e entidades da administração pública federal ou municipal; III - doaçóes realizadas por entidades nacionais e internacionais, públicas ou privadas; IV - empréstimos de instituiçōes financeiras nacionais ou internacionais; Vreversão dos saldos anuais não aplicados (PARAÍBA, 2013).

Para Reis (2015) as diversas legislaçóes de PSA no Brasil podem ser interessantes na medida em que tem o potencial de revelar é proporcionar maior custo-efetividade ao programa, mas isso vai depender das condiçóes socioeconômicas locais e do seu desenho, tendo em vista tudo o que aqui foi exposto, que os programas de pagamentos por serviços ambientais são considerados precursores de alianças entre o setor público e privado com um objetivo em comum: a conservação ambiental, fato imprescindível ao desenvolvimento econômico atual e futuro.

Sendo o JBBM um bem natural de todos, é seguindo o princípio do protetorrecebedor, o mais indicado é que o provedor seja o próprio local, já que é a geradora dos serviços ambientais, é que todo o retorno financeiro seja depositado em açóes, como, estudos científicos, zoneamento e melhoria para o local. Conforme aponta Reis (2018) sobre a primeira experiência posta em pratica no estado de Pernambuco, o programa Água do Parque, um projeto de PSA no Parque Estadual Dois Irmãos Recife-PE. Foi iniciado entre os anos de 2011/2012 e concluído em 2013. A área beneficiada é de 264 hectares, a área de impacto de 600 hectares. O valor arrecadado era investido em melhorias ambientais e de infraestrutura para o local.

\subsection{Potencialidades para o Pagamento por Serviços Ambientais (PSA) no jardim botânico Benjamim Maranhão, João Pessoa (PB)}

Assim como outros ambientes naturais, os Jardins Botânicos participam da estratégia de conservaçáo. Isso porque seus objetivos são preservar, proteger espécies silvestres raras ou ameaçadas de extinção; resguardar espécies econômica e ecologicamente importantes para 
a restauração ou reabilitação de ecossistemas; realizar, de forma sistemática e organizada, registros referentes ao acervo vegetal; pesquisa científica; lazer e educação (BRASIL, 2000).

A área onde atualmente localiza-se o Jardim Botânico foi adquirida pelo Estado em 1907 para dar início às obras de abastecimento de água da cidade de João Pessoa. O serviço de abastecimento foi inaugurado em 1912 e funcionava através de 33 poços construídos ao longo da Mata Atlântica, bombeados por duas caldeiras a vapor. Em 1940 foi inaugurada a Barragem do Buraquinho, que represou o Rio Jaguaribe para melhorar a realimentação do lençol freático (LUCENA, 2002), o projeto deu início ao processo de desmatamento e degradação da área, tanto com a abertura de avenidas e estradas quanto com a passagem da tubulação e construção de equipamentos (GADELHA NETO e SANTOS, 2002).

A partir da década de 1940, o sistema de abastecimento de água através de poços foi sendo gradativamente extinto. Assim, foram elaboradas novas propostas de "aproveitamento" e exploração da Mata do Buraquinho. Após algumas tentativas de implementação de um Jardim Botânico na Mata do Buraquinho, só em 28 de agosto de 2000, a partir do Decreto Estadual $n^{\circ}$ 21.264, efetivou-se a criação do Jardim Botânico Benjamim Maranhão JBBM - como unidade orgânica diretivo executivo, dentro da estrutura organizacional da SUDEMA - Superintendência de Administração do Meio Ambiente. Mas só em 23 de março de 2002 foi inaugurado o JBBM, após um longo e delicado processo de elaboração do seu plano de manejo, que definiu como prioridade para a área o desenvolvimento de atividades que envolvam "preservação, pesquisa científica, educação ambiental, e lazer contemplativo" (GADELHA NETO, 2005, p.25).

A construção do referido Jardim Botânico objetiva, além da preservação dos recursos naturais pertencentes à área de Mata Atlântica, a implementação de um programa de educaçáo ambiental bastante amplo e participativo, sendo resguardado por um decreto de competências legais (Quadro 4).

Quadro 4: Decreto de competências legais do Jardim Botânico Benjamin Maranhão

1. Promover a pesquisa, a conservação, a educação ambiental e o lazer compatível com a finalidade de difundir o valor multicultural das plantas e a sua utilização sustentável.

2. Proteger, inclusive por meio de tecnologias apropriadas de cultivo, espécies silvestres, raras ou ameaçadas de extinção, especialmente em nível local e regional, bem como resguardar espécies econômicas e ecologicamente importantes para restauração ou reabilitação do ecossistema.

3. Manter reservas genéticas in-situe/ou bancos de germoplasma ex-situ.

4. Realizar, de forma sistemática e organizada, registros de documentação de plantas, referentes ao acervo vegetal, os quais permanecem acessíveis, no seu todo ou em parte, aos usuários, visando plena utilização para conservaçáo da natureza.

5. Promover intercâmbio científico, técnico e cultural com entidades e órgãos nacionais e estrangeiros.

6. Estimular e promover a capacitação de recursos humanos.

7. Permitir o acesso aos recursos genéticos, considerando a proteção ao Patrimônio Nacional, conforme legislação específica.

Fonte: Autores, (2018). 
De acordo com Araujo (2002) tais atribuições visam à conservação da Mata Atlântica no Nordeste e o desenvolvimento e manutenção de coleções documentadas de plantas características da localidade, bem como outros espécimes botânicos que estejam adaptados à zona climática nordestina. Dada as formas de uso do jardim botânico, perante a legislação de criação e suas competências junto a legislação de PSA para o Estado junto as suas atribuiçóes é notório a potencialidade do local para aplicação de um programa de PSA.

Segundo Kiyotani e Tavares (2016) o Jardim Botânico Benjamin Maranhão é de grande atratividade para o público, ao ser possível desfrutar da valia que tem esse ecossistema, desse modo, recai sobre o Jardim uma responsabilidade ainda maior de preservar estes recursos. Neste sentido, um programa de PSA, poderia ajudar economicamente o local, aproveitando de sua estrutura de serviços ambientais ofertada pelo ecossistema.

De acordo com Kiyotani e Tavares (2016) o Jardim Botânico vem servindo tanto para os benefícios dos animais como para o homem; os autores observam pontos que recebem benesses do JBBM: indústria, medicina, produção de fármacos, ornamentação e abrigo para os animais da reserva, purificação do ar, regulação do clima e pluviosidade. Assim, mostra-se claramente a importância do ambiente a ser preservado e suas funçôes ambientais.

Constata-se a partir da dissertação de Araújo (2002) sobre o valor dos serviços ambientais ofertados pelo Jardim Botânico Benjamin Maranhão, a existência de resultados referentes à Disposição A Pagar (DAP) para a área, onde 49,8\% dos entrevistados declarou um valor. Ou seja, metade da amostra está disposta a pagar algum valor não nulo para a efetivação e manutenção do Jardim Botânico. Ainda no trabalho de Araújo (2002), o valor médio da Disposição A Pagar (DAP) dos entrevistados foi de R $\$ 2,68$. Desse modo observa-se a tangibilidade e a passibilidade para inclusão de uma PSA para o território em conservação pertencente a mata do buraquinho/Jardim Botânico Benjamim Maranhão.

O intuito deste artigo não é a cobrança de ingresso para o local tampouco valora-lo, mas afirmar e apontar através da literatura e legislação já documentada as potencialidades para o enquadramento em algum subprograma de PSA para o JBBM. Os pontos ambientais observados na mata do buraquinho e no Jardim Botânico poderão ser ainda mais conservados caso esses se envolvam e desenvolvam algum dia, projetos que venha a captar recursos para sua manutenção, zoneamento e fiscalização eficiente e contínuo, bem como investimentos em estudos científicos no local. Fica evidente que o Jardim Botânico Benjamin Maranhão, apresenta uma forte potencialidade para um programa de PSA na Paraíba, para que futuramente venha aproveitar do Fundo Estadual de Pagamento por Serviços Ambientais (FUNPSA) conforme aponta a Lei no 10.165/13.

\section{CONSIDERAÇÓES FINAIS}

O mecanismo de PSA poderia ser um importante aliado na conservação do local, podendo envolver a população que está próxima, os enquadrando como protetores e conservacionistas, tendo a fiscalização própria do Jardim Botânico como os provedores. O Jardim Botânico Benjamin Maranhão, apresenta todas as características pedidas nos subprogramas do PSA na Paraíba, podendo ser enquadrado para a habilitação do PROPSAPB. Para que isto aconteça é necessária a viabilidade de estudos técnicos por parte dos 
gestores públicos, a fim de ser valorar o ecossistema da Mata do Buraquinho e ver qual subprograma apresenta melhor rentabilidade para o PSA.

A definição do serviço ambiental que vai ser transacionado é de grande importância, já que este precisa ser bem definido. Neste sentido, a indicação aqui é do serviço ambiental de regulação, por que correspondem diretamente ao subprograma remanescentes vegetais em áreas urbanas e periurbanas, destinado ao pagamento por açóes e iniciativas de preservaçáo de remanescentes vegetais de importância para a manutenção e o melhoramento da qualidade do ar, dos recursos hídricos e do bem-estar da população. Este é o mais indicado para o Jardim Botânico Benjamin Maranhão, de acordo com a Lei no 10.165/13.

Por fim, a análise feita neste artigo não pretende abordar uma relação econométrica de valoração ambiental dos serviços ambientais, para a criação de um PSA para o jardim botânico, sugerindo um valor de entrada no local, e sim, um programa que venha trazer subsídios de maneira legal para fins de melhoria de infraestrutura e conservação ambiental da área, onde o Jardim Botânico Benjamin Maranhão, apresenta um forte potencial para um PSA dos seus serviços ambientais.

\section{REFERÊNCIAS}

ALTMANN, A. Pagamento por serviços ambientais como mecanismo econômico para mitigação das mudanças climáticas no Brasil. In RECH, Adir Ubaldo (Org.). Direito e Economia Verde. Natureza jurídica e aplicaçóes práticas de pagamentos por serviços ambientais, como instrumento de ocupaçóes sustentáveis. Caxias do Sul: Educs, 2011. p. $02-25$.

ANDRADE, D.C. Modelagem e Valoraçáo de Serviços Ecossistêmicos: Uma contribuiçáo da Economia Ecológica. 2010. 269 f. Tese (Doutorado em Economia) Instituto de Economia, Universidade Estadual de Campinas, Campinas, 2010.

ANDRADE, D.C.; ROMEIRO, A.R. Serviços ecossistêmicos e sua importância para o sistema econômico e o bem-estar humano. Campinas - SP: IE/UNICAMP. n. 155, fev. 2009.ISSN 0103-9466.

ARAÚJO, A. F.V. de. Valorizaçáo ambiental uma aplicaçáo do modelo logit para a avaliaçáo monetária do Jardim Botânico da cidade de Joáo Pessoa. 2002. 120 f. Dissertação (Mestrado em Economia) - Centro de Ciências Sociais e Aplicadas/ Universidade Federal de Pernambuco, 2002.

BARRETO, E.S. Crise ambiental e a Ciência Econômica: uma crítica à teodiceia do capitalismo "verde". In: IACR [International Association for Critical Realism XII Annual Conference], jul/2009. Disponível em: <http://www.uff.br/iacr/ArtigosPDF/52T. pdf $>$. Acesso em 09 jan. de 2018. 
BECKER, B. Amazônia: projeto nacional, política regional e instrumentos econômicos. In: MAY, Peter H. et al. (orgs.). Instrumentos econômicos para o desenvolvimento sustentável na Amazônia brasileira. Brasília: Ministério do Meio Ambiente, 2005.

BRASIL. Lei 9.433, de 08 de Janeiro de 1997. Institui a Política Nacional de Recursos Hídricos, cria o Sistema Nacional de Gerenciamento de Recursos Hídricos, regulamenta o inciso XIX do art. 21 da Constituição Federal, e altera o art. $1^{\circ}$ da Lei no 8.001, de 13 de março de 1990, que modificou a Lei no 7.990, Diário Oficial da Uniáo, Brasília, de 28 de dezembro de 1989.

BRASIL, 1997 DECRETO DE 23 de outubro de 1997. Dispõe sobre a criação da área de Proteção Ambiental da Costa dos Corais, nos Estados de Alagoas e Pernambuco, e dá outras providências. Diário Oficial da União, Brasília, 24 de outubro de 1997, seção 1, 206: p. 24062 .

BRASIL. Ministério do Meio Ambiente. Convenção sobre Diversidade Biológica. Braulio F. S. Dias (Org.). Brasília: Série Biodiversidade, 2000.

BRASIL. Ministério do Meio Ambiente. SNUC - Sistema Nacional de Unidades de Conservação da Natureza: Lei no 9.985, de 18 de julho de 2000; Decreto no 4.340, de 22 de agosto de 2002; Decreto no 5.746, de 5 de abril de 2006. Plano Estratégico Nacional de Áreas Protegidas: Decreto no 5.758, de 13 de abril de 2006., Diário Oficial da Uniáo, Brasília: MMA, 2011. 76 p.

BRASIL. Conselho Nacional do Meio Ambiente - CONAMA. Resoluçáo n. 266, de 03 de Agosto De 2000. Dispóe sobre o uso das competências que lhe são conferidas pela Lei no 6.938, de 31 de agosto de 1981, 2000. Disponível em: <http://www.mma.gov.br/ port/conama/res/res00/res26600.html>. Acesso em: 10 jan. 2018.

BRASIL. Lei 12.651, de 25 de Maio de 2012. Dispóe sobre a proteção da vegetação nativa; altera as Leis nos 6.938, de 31 de agosto de 1981, 9.393, de 19 de dezembro de 1996, e 11.428, de 22 de dezembro de 2006; revoga 96 as Leis nos 4.771, de 15 de setembro de 1965, e 7.754, de 14 de abril de 1989, e a Medida Provisória no 2.166-67, de 24 de agosto de 2001; e dá outras providências, Diário Oficial da Uniáo, Brasília.

CAVALCANTI, C. Uma Tentativa de Caracterização da Economia Ecológica. Ambiente \&Sociedade, São Paulo, vol. 7, n. 1, p. 149-156, jan. - jun. 2004.

CAVALCANTI, C. Concepçóes da economia ecológica: suas relaçóes com a economia dominante e a economia ambiental. Revista Estud, v. 24, n. 68, p. 22-35, fev. 2010.

CECHIN, A.; VEIGA, J. E. da. O fundamento central da economia ecológica. In: Economia do Meio Ambiente. Peter May (org.). 2. ed. Rio de Janeiro: Elsevier, 2010. 
COASE, R. H. The problem of Cost. Journal of lawand Economics, Virginia, p.01-44, octuber, 1960.

CONSTANZA, R., Alperovitz, G., Daily, H., Farley, J., \& Franco, C. (2012).Building a Sustainable and Desarible Economy-in-Society-in-Nature. Report to the United Nations for the 2012 Rio +20Conference as part of the Sustainable Devolopment in the 21st Century.

CUNHA, F. A. G. C. da. Unidades de conservaçáo como fornecedoras de serviços ambientais / Fábio Adônis Gouveia Carneiro da Cunha. - Recife. 2014. Dissertação (Mestrado em Desenvolvimento e Meio Ambiente). Universidade Federal de Pernambuco. Recife-PE, 2014.

CFT. Projeto de Lei n. 792, de 2007. Dispóe sobre a definiçáo de serviços ambientais e dá outras providências. Comissão de Finanças e Tributação. 2014.Disponível em: <http://www.camara.gov.br/proposicoesWeb/fichadetramitacao?idProposicao=3487 83> Acesso em: 08 de jan. 2018.

DAILY, G. C. Nature's Services: Societal Dependence on Natural Ecosystems. Washington: Island Pres, 1997.

ENGEL, S.; PAGIOLA, S.; WUNDER, S. Designing payments for environmental services in theory and practice: an overview of the issue. Ecological Economics, v. 65, p. 663-674, May, 2008.

FIGUEROA, J. R. Valoración de labiodiversidad: perspectiva de la economia ambiental y la economia ecológica. Revista INCI online, 2005. Disponível em: $<$ http:// www.scielo.org.ve/scielo.php?pid=S037818442005000200011\&script=sci_arttext>. Acessoem: 23 mai de 2017.

FOOD AND AGRICULTURE ORGANIZATION. Payment Schemes for Environmental Services in Watersheds. Land and Water Discussion. Paper3. Roma, 2004.

GADELHA NETO, P. C.; SANTOS, M. C. Relatório técnico científico. João Pessoa: JBBM, 2002.

GADELHA NETO, P. C. Noçóes gerais sobre jardins botânicos. João Pessoa: JBBM, 2005.

GELUDA, L. ; YOUNG, C. E. F. Pagamentos por serviços ecossistêmicos previstos na lei do SNUC - teoria, potencialidades e relevância. In: III SIMPÓSIO DE ÁREAS PROTEGIDAS, 2014, Pelotas. Anais eletrônicos..., Pelotas: UCP,2005. Disponível em:<http://www.ie.ufrj.br/images/gema/Gema_Artigos/2005/GeludaYoung_2005_ psesnuc.pdf $>$ Acesso em: 18 de jan. de 2018. 
GIL, A. C. Como elaborar projetos de pesquisa. 5. ed. São Paulo: Atlas, 2010.

GUEDES, F. B.; SEEHUSEN, S. E. Pagamentos por serviços ambientais na mata atlântica: liçóes aprendidas e desafios. Brasília: MMA, 2011.

IBGE. Anuário estatístico do Brasil. 1992.

IBGE. Anuário estatístico do Brasil. 1992.

IUCN. 2000. Financing Protected Areas: Guidelines for Protected Area Managers. Gland, Switzerland: IUCN, Cardiff University.

KIYOTANI, I.B.; SOUSA, F.G.; TAVARES, A.G. Turismo em Unidades de Conservação: o Jardim Botânico Benjamim Maranhão, João Pessoa (PB). Revista Brasileira de Ecoturismo, São Paulo, v.8, n.5, 2016, p.684-707.

KOSOY et al. Payments for Environmental Services in Watersheds: Insights from a comparative study of three cases in Central America. Ecological Economics. 61(2-3): 446-455, 2007.

LANDELL-MILLS, N.; PORRAS, T.I. Silver bullet or fools' gold? A global review of markets for forest environmental services and their impact on the poor. Instruments for sustainable private sector forestry series. International Institutefor Environmentand Development, Londres, 2002.

LUCENA, E. Jardim Botânico Benjamim Maranhão. João Pessoa: SUDEMA, 2002.

MARTINS, Rafael D'Almeida. A importância da economia ecológica para o debate sobre a possibilidade de crescimento econômico com "sustentabilidade". Centro de Estudos e Pesquisas em Políticas Sociais e Qualidade de Vida, São Paulo, jul. 2007. Disponível em: <www.cepps.org.br/artigo/economia-ecologica-crescimento-economico>. Acesso em: 09de jan. 2018.

MEDEIROS, R.; Y. ; C.E.F.; PAVESE, H. B.; ARAÚJO, F. F. S. Contribuição das unidades de conservação brasileiras para a economia nacional: Sumário Executivo. In: Nations Environment Programme - World Conservation Monitoring Centre, Brasilia, 2011.

MILARÉ, É. Direito do Ambiente. 8ª ed. São Paulo: Editora Revista dos Tribunais, 2013.

MILLENNIUM Assessment. Ecosystems and Human Well-being. A Framework for assessment. Washington: Island Press, 2003. 155 p. ISBN 1-59726-040-1.

MA - MILLENNIUM ECOSYSTEM ASSESSMENT. Ecosystems and Human

Wellbeing: a Framework for Assessment. Washington: Island Press, 2005. 
MOTA, J. A. O valor da natureza, economia e política dos recursos naturais. In: OLIVEIRA, J. M. L. (Org.). Rio de janeiro: Garamond, 2001.

MOTTA, R. S. da. Economia Ambiental. Rio de Janeiro: FGV, 2006.

NUSDEO, A.M.O. Pagamento por serviços ambientais: sustentabilidade e disciplina jurídica. Sáo Paulo: Atlas, 2012.

PARAÍBA. Lei no 10.165, de 25 de novembro de 2013. Dispóe sobre a Política Estadual de Pagamento por Serviços Ambientais, autoriza instituir o Fundo Estadual de Pagamento por Serviços Ambientais, e dá outras providências. Diário Oficial do Estado, João Pessoa, PB, 26 nov. 2013. Disponível em: <http://static.paraiba.pb.gov.br/2013/11/ Di\%C3\%A1 rio-Oficial-26.11.2013.pdf>. Acesso em: 12 jan. de 2018.

PACKER, L.A. Novo Código Florestal e Pagamentos por Serviços Ambientais: Regime Proprietário sobre os Bens Comuns. Curitiba: Juruá, 2015.

PEARCE, D. Economic Valuation and the Natural World. Washington: World Bank, 2001.

PUGAS, M. A. R. Valoração contingente de unidades de conservação: avaliando s DAP espontânea e induzida da populaçáo de Rondonópolis (MT) pelo horto Florestal. 2006.130 f. Dissertação (Mestrado em Gestão Econômica do Meio Ambiente) Universidade de Brasília, Brasília, 2006.

REIS, J. V. Pagamento por serviços ambientais: instrumento de incentivo à preservação ambiental. Revista Brasileira de Gestáo Ambiental e Sustentabilidade. v. 2, n. 3, p. 79 87. Dez. 2015.

REIS, J. V. Histórico de projetos sobre Pagamento por Serviços Ambientais (PSA) no estado de Pernambuco (Brasil). Revista Brasileira de Meio Ambiente. n.1, v.1. p. 007$010,2018$.

ROCHA, J. M. da. A ciência econômica diante da problemática ambiental. Universidade de Caxias do Sul, 2004.

SANTANA, J. R. T. Valoração econômica e conservaçáo do meio ambiente: explorando a disposiçáo a pagar de uma comunidade de baixa renda. Brasília, 2002. 78 f. Dissertação (Mestrado em Gestão Econômica do Meio Ambiente), Departamento de Economia, Instituto de Ciências Humanas, Universidade de Brasília, 2002.

SACHS, I. Ecodesenvolvimento: crescer sem destruir, Terra dos Homens. São Paulo: Vértice, 1986. 
SINISGALLI, P. A. de A. Valoração dos danos ambientais de hidrelétricas: estudos de caso. 2005. 226 f. Tese (Doutorado em economia). Instituto de Economia, Universidade Estadual de Campinas - UNICAMP, 2005.

SUKHDEV, P. T. The Economics of Ecosystems and Biodiversity: Mainstreaming the Economics of Nature: A synthesis of the approach, conclusions and recommendations of TEEB, 2010.

TACCONI, L., Redefining payments for environmental services. Ecological Economics. v.73, p. 29-36. 15 January. 2012.

TAFURI, A. C. Valoraçáo ambiental do Parque Estadual do Itacolomi, Ouro Preto, Minas Gerais. 2008. 158 f. Dissertação (Mestrado em Saneamento, Meio Ambiente e Recursos Hídricos) - Universidade Federal de Minas Gerais, Belo Horizonte, 2008.

TÔSTO, S. G.; PEREIRA, L. C.; MANGABEIRA, J. A. de C. Serviços ecossistêmicos e serviços ambientais: conceitos e importância! Portal Ecodebate. dez. 2012. Disponível em: <http://www.ecodebate.com.br/2012/12/13/servicos-ecossistemicos-e servicos ambientais- conceitos-e-importancia-artigo-de-sergio-gomes-tosto-lauro-charletpereirae-joao-alfredo-de-c-mangabeira/>. Acesso em 10 jan. 2018.

TURNER, K. T. et al. Valuing nature: lessons learned and future research directions. Ecological Economics. n. 46, p. 493-510, 2003.

VASCONCELLOS, C.S. Avaliação concepção dialética - libertadora do processo de avaliação escolar. São Paulo: Libertad, 2005.

VEIGA NETO, F. C. da; MAY, P. H. Mercados para serviços ambientais. In: Economia do Meio Ambiente. Peter May (org.). 2. ed. Rio de Janeiro: Elsevier, 2010.

WUNDER, S. Pagamentos por serviços ambientais: perspectivas para a Amazônia Legal. Coordenador; Jan Börner, Marcos Rügnitz Tito e Lígia Pereira. 2a . ed., rev. Brasília: MMA, 2009.

WUNDER, S.; WERTZ-KANOUNNIKOFF, S. Payment for Ecosystems Services: A New Way of Conserving Biodiversity in Forests. Journal of Sustainable Forestry, 2009. ISSN: 1054-9811.

WUNDER, S. Revisiting the concept of payments for environmental services, Ecological Economics, 2005.

WHATELY, M.; HERCOWITZ, M. Serviços ambientais: conhecer, valorizar e cuidar: subsídios para a proteção dos mananciais de São Paulo. São Paulo: Instituto Socioambiental, 2008. 